\title{
Fading Characteristics Observed on a High-Frequency Auroral Radio Path
}

\author{
J. W. Koch ${ }^{1}$ and H. E. Petrie \\ Contribution from Central Radio Propagation Laboratory, National Bureau of Standards, Boulder, Colo.
}

(Received June 22, 1961; revised September 14, 1961)

\begin{abstract}
Observations of fading characteristics of high-frequency signals have been carried out on a long path $(4,470$ kilometers $)$ passing through the auroral zone. Statistics were obtained on fading rate, short-term carrier amplitude fluctuations, and fade durations. Fading rates higher than 20 cycles per second were observed for a small percentage of the time at each of the three carrier frequencies used, and show only a minor diurnal trend, with the maximum usually occurring during the early morning hours. Rayleigh distributions of carrier envelope amplitude were obtained for many of the observations; however, fading depth was normally reduced during periods of rapid fading.
\end{abstract}

\section{Introduction}

The characteristics of carrier envelope amplitude fluctuations, or fading, must be considered in attempting to predict the performance of radio systems. Fading on high-frequency ionospheric links may be caused by changes in absorption of the waves, by interference between two or more components of the waves arriving by different paths or by changes in polarization of the downcoming waves. Absorption fading is usually much slower than the other types. Movement of ionospheric layers and irregularities in the ionosphere cause changes in phase path lengths and in the state of polarization of the multipath components, accounting for the more rapid amplitude fluctuations. A very rapid fading, sometimes referred to as "flutter" fading, has been observed for many years on high-frequency paths passing through or near the auroral zone.

Several investigators [Rice, 1944, 1945, 1948, 1958; McNicol, 1949; Norton, Vogler, Mansfield, and Short, 1955; Norton, Rice, Janes, and Barsis, 1955] have made theoretical analyses of carrier fading, considering the problem on the basis of envelope behavior for narrow-band Gaussian noise models, with or without steady components. Observations of certain short-term high-frequency propagation characteristics have been performed by many workers in the field, for example, Grisdale, Morris, and Palmer [1957], Aggarwal [1959], and Yeh and Villard [1960]. The purpose of the observations reported in this paper is to provide some additional statistical information on short-term fading characteristics for signals propagated on a long path through auroral regions. Results of the observations are presented in several different forms; the intent is to give as clear a picture as possible of the observed statistical behavior of carrier envelope fading on the path.

${ }^{1}$ Present address: Ball Brothers Research Corp., Boulder, Colo.

\section{Experimental Facilities}

Observations were carried out over a path from Barrow, Alaska, to Boulder, Colo., during 1959 and 1960 , at frequencies of $9.9475 \mathrm{Mc} / \mathrm{s}, 14.688 \mathrm{Mc} / \mathrm{s}$, and $19.247 \mathrm{Mc} / \mathrm{s}$. The great circle distance is $4,470 \mathrm{~km}$. Figure 1 shows the geographic location of the path relative to the undisturbed auroral zone.

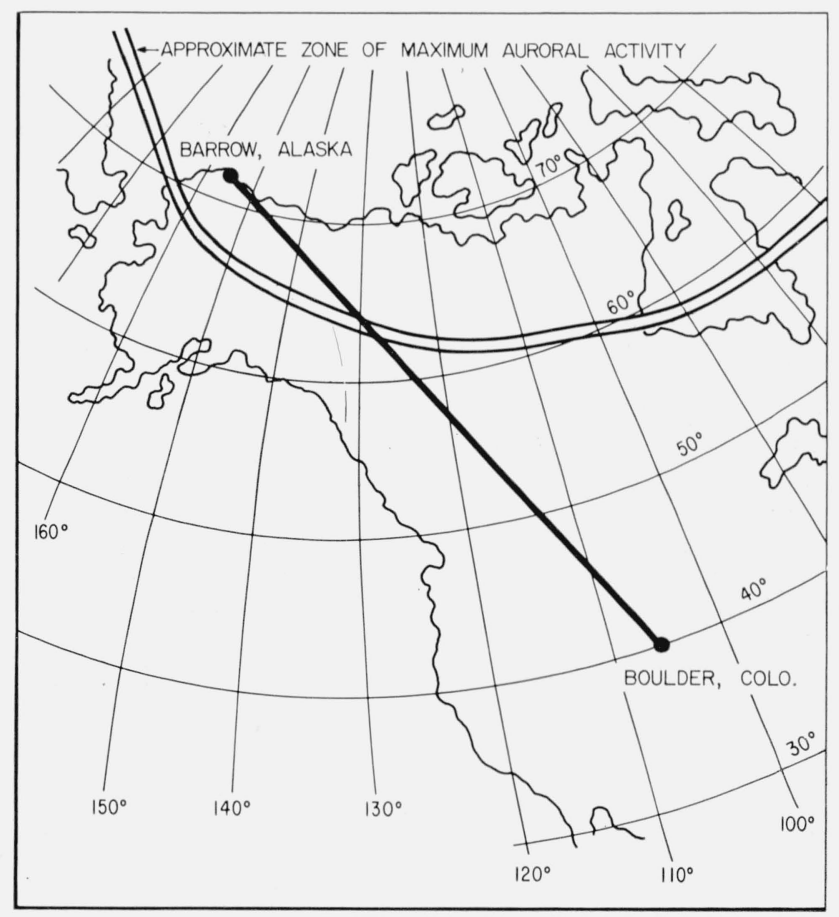

Figure 1. Geographic location of transmitter and receiver stations. 


\subsection{Transmitting and Receiving Stations}

The transmitting station was set up at the camp of the Arctic Research Laboratory, Barrow, Alaska, with three $3 \mathrm{kw}$ transmitters. All transmitters had precise carrier frequency control, with stability of better than one part in $10^{8}$ per day. The transmitters were operated with unmodulated steady carrier for these observations.

The receiving station was set up at the National Bureau of Standards Table Mesa field site near Boulder, Colo. Receiving equipment consisted of high quality communication type receivers with external heterodyne oscillators. The oscillator stability was within one part in $10^{8}$ per day. Modifications were made in the receivers to provide a 1-msec time constant in the automatic gain control (AGC) circuits. An external envelope detector with a 2 -msec time constant was used to provide the AGC voltage for each receiver and to supply an envelope voltage for recording purposes. An intermediate frequency translated down from the carrier frequency was also available for operating continuous fading rate recording equipment. A twelve-second time constant was used in the AGC circuit when the receivers were used for continuous fading rate recording. The receiving antennas at the Table Mesa site were half-wavelength horizontal dipoles at a height of one wavelength above the ground.

\subsection{Data Recording and Analysis Equipment}

\section{a. Fading Rate Recorder}

Each receiver had an associated fading rate recorder which operated continuously except for short periods when recordings were being made for other fading analysis. The fading rate instruments [Koch, Harding, and Jansen, 1960] record on paper charts the average number of times per second the instantaneous carrier envelope voltage crosses the six-second average carrier envelope level with a positive slope. Fading rates recorded by this instrument may differ by a very small amount from fading rates as defined by Norton, Rice, Janes, and Barsis [1955], i.e., the number of times per second the instantaneous envelope voltage crosses the median level with a positive slope.

\section{b. Instantaneous Carrier Envelope Voltage Recording and Analysis Equipment}

Instantaneous carrier envelope voltages at the outputs of the receiver envelope detectors were recorded on magnetic tape for later analysis. The FM recording technique was employed, wherein the detector output voltages modulate FM subcarriers in the tape recording equipment.

An amplitude distribution analyzer and fade duration analyzer were used with the tape reproducing equipment to obtain statistics on the fine grain fluctuations of the fading signals. The amplitude distribution analyzer samples the carrier envelope voltage 1,000 times per second with $50 \mu$ sec pulses, and displays on decade counters the percentage of time the carrier envelope voltage exceeds threshold levels set at $5 \mathrm{db}$ intervals. The fade duration analyzer displays on decade counters the percentage of time the carrier envelope fades to and remains below preset levels for various minimum durations of fades. Fade durations from 2.5 to $500 \mathrm{msec}$ were analyzed in this manner. Fading rates at different carrier levels relative to the median and for different durations of fades are also obtained with this equipment.

\section{Carrier Envelope Fading Characteristics}

\subsection{Theoretical Curves}

It is of interest to examine the behavior of fading signals based on assumed theoretical model of the propagating medium. The theoretical curves presented here have been derived by reference to the considerable amount of work by S. O. Rice [1958]. He has assumed that the envelope voltage of the received radio wave varies in the same manner as the envelope of narrow-band Gaussian noise (Rayleigh distributed) having a normal-law power spectrum centered on the transmitter frequency.

The probability that the duration of a fade equals or exceeds a time $T$ seconds in length for a given crossing level has been developed by Rice [1958]. The following expression has been applied to his results to obtain a family of curves, figure 2 , showing the distribution of carrier envelope amplitudes for various minimum durations of fades:

$$
P\left(D_{T}, R\right)=P\left(D_{T} \mid R\right) P(R)
$$

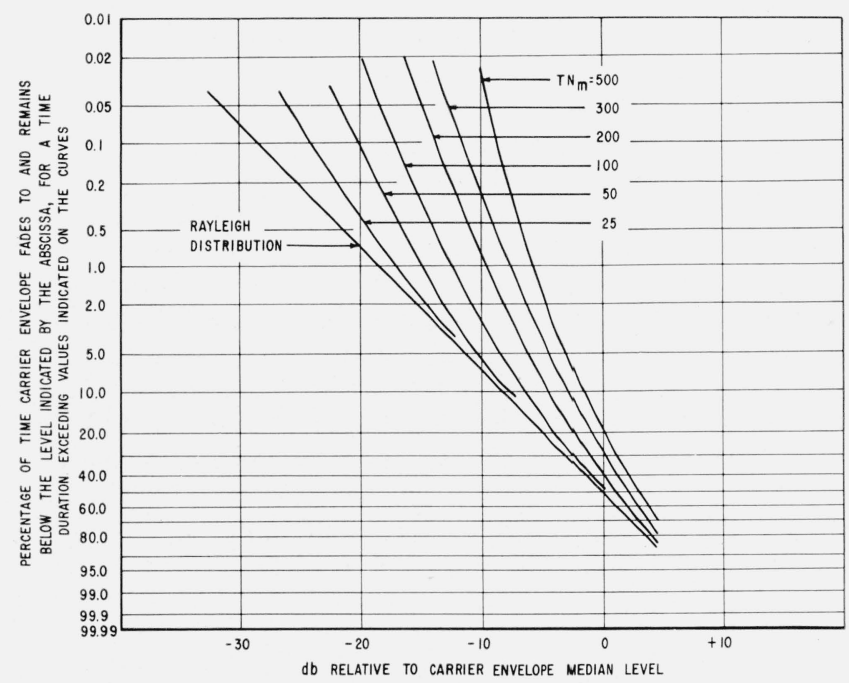

FIGURE 2. Theoretical distributions of carrier envelope amplitude for various minimum fade durations.

$T$ is minimum duration of fades in milliseconds. $N_{m}$ is average number of times per second carrier envelope voltage passes downward across median level; narrow-band Gaussian random noise model with normal-law power spectrum. 
where

$P(R)=$ probability that instantaneous carrier envelope voltage is equal to or less than $R$ for a Rayleigh fading signal;

$P\left(D_{T} \mid R\right)=$ conditional probability that a fade has a duration equal to or exceeding $T$, given that the crossing level is $R$;

$P\left(D_{T}, R\right)=$ probability that the carrier envelope voltage fades to and remains below the level $R$ for a time duration equal to or exceeding $T$.

When the minimum fade duration is such that all fades are included, the distribution becomes Rayleigh.

Figure 3 is a plot of theoretical average fading rates versus crossing levels relative to the median carrier envelope level, using the expression [Rice, $1958]$ :

where

$$
\frac{N_{R}}{N_{m}}=2 \frac{E_{R}}{E_{m}}\left(\frac{1}{2}\right)^{E_{R}^{2} / E_{m}^{2}}
$$

$N_{R}=$ average fading rate (all fades) at level $R$;

$N_{m}=$ average fading rate (all fades) at median level; $E_{R}=$ carrier envelope voltage at level $R$;

$E_{m}=$ median carrier envelope voltage.

Figure 4 shows theoretical fading rates versus minimum fade durations for various crossing levels, based on the assumption that,

where

$$
N_{T R}=P\left(D_{T} \mid R\right) N_{R}
$$

$N_{T R}=$ average fading rate for minimum fade duration $T$ at crossing level $R$.

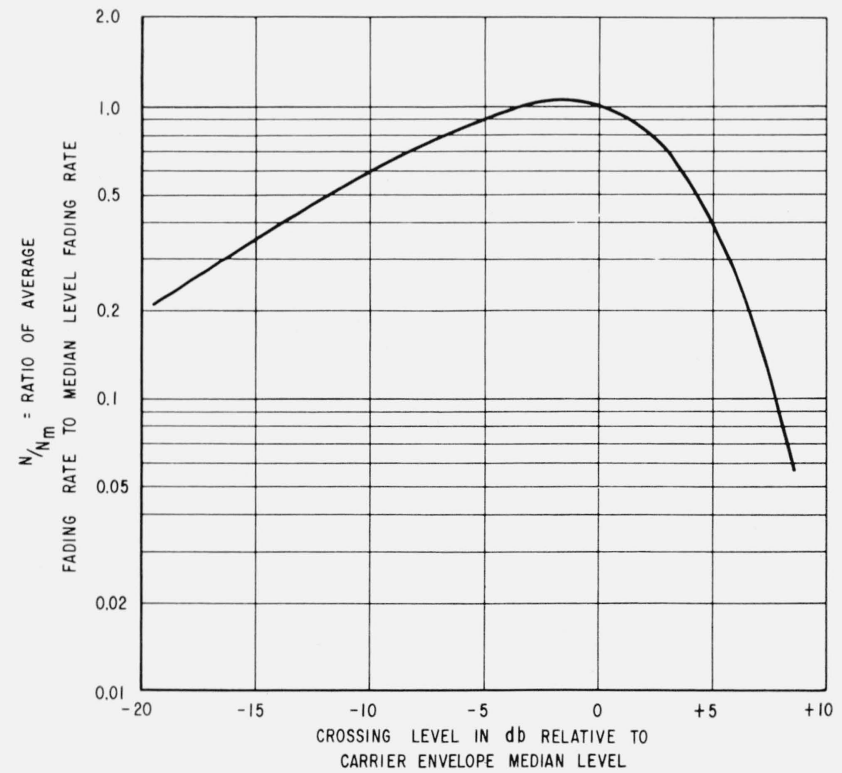

Figure 3. Theoretical fading rate versus crossing level for narrow-band Gaussian noise model.

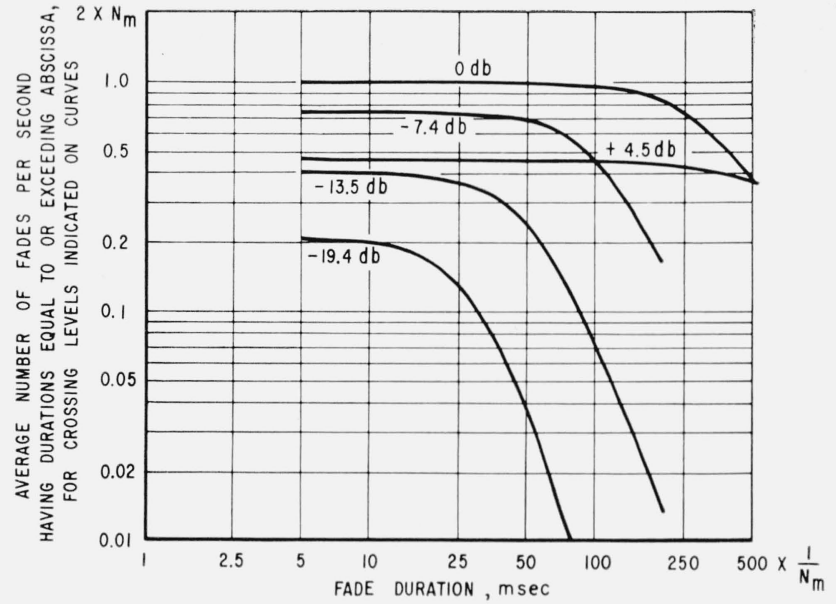

Figure 4. Theoretical fading rate versus minimum fade duration for indicated carrier levels relative to median carrier envelope level.

$N_{m}$ is a verage number of times per second carrier envelope voltage passes downward across median level; narrow-band Gaussian random noise model.

\subsection{Observed Fading Rates}

Average fading rate observations have been carried out during the period from August 1959 through January 1960 on the Barrow to Boulder path. The recordings have been scaled for hourly maximum and 10 -min fading rates.

Figures 5 and 6 are plots of diurnal variations of fading rates for the months of October 1959 and
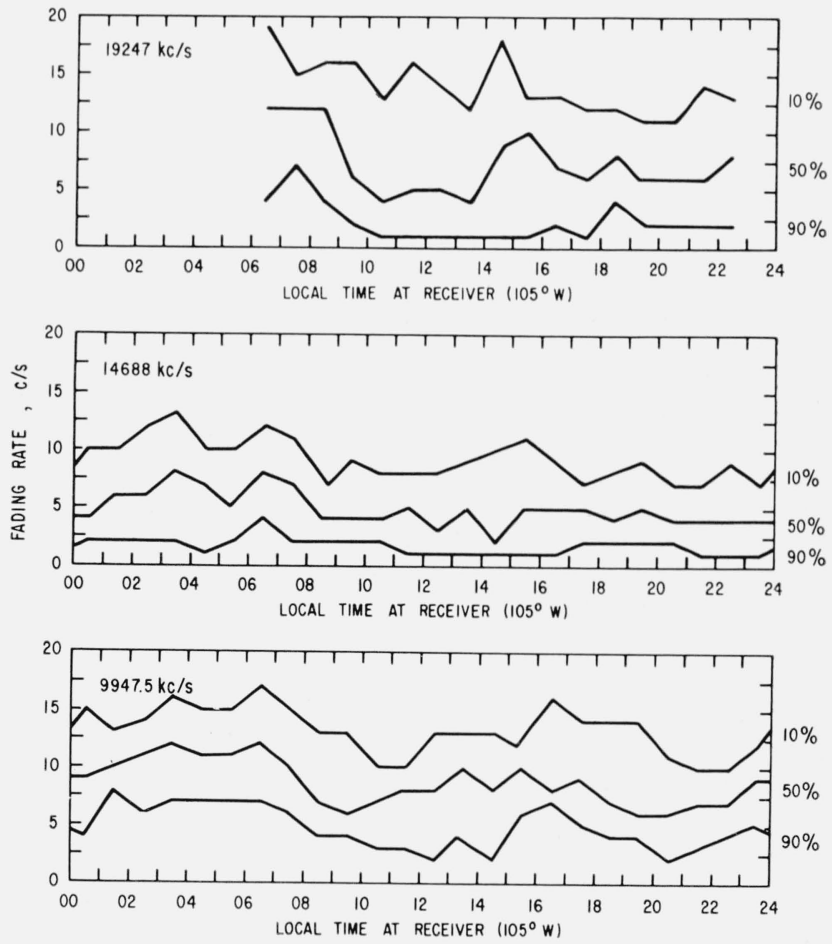

FiguRE 5. Diurnal variations of hourly maximum fading rates, October 1959. Hourly maximum fading rates are exceeded for percentage of time indicated by
curve parameters. 

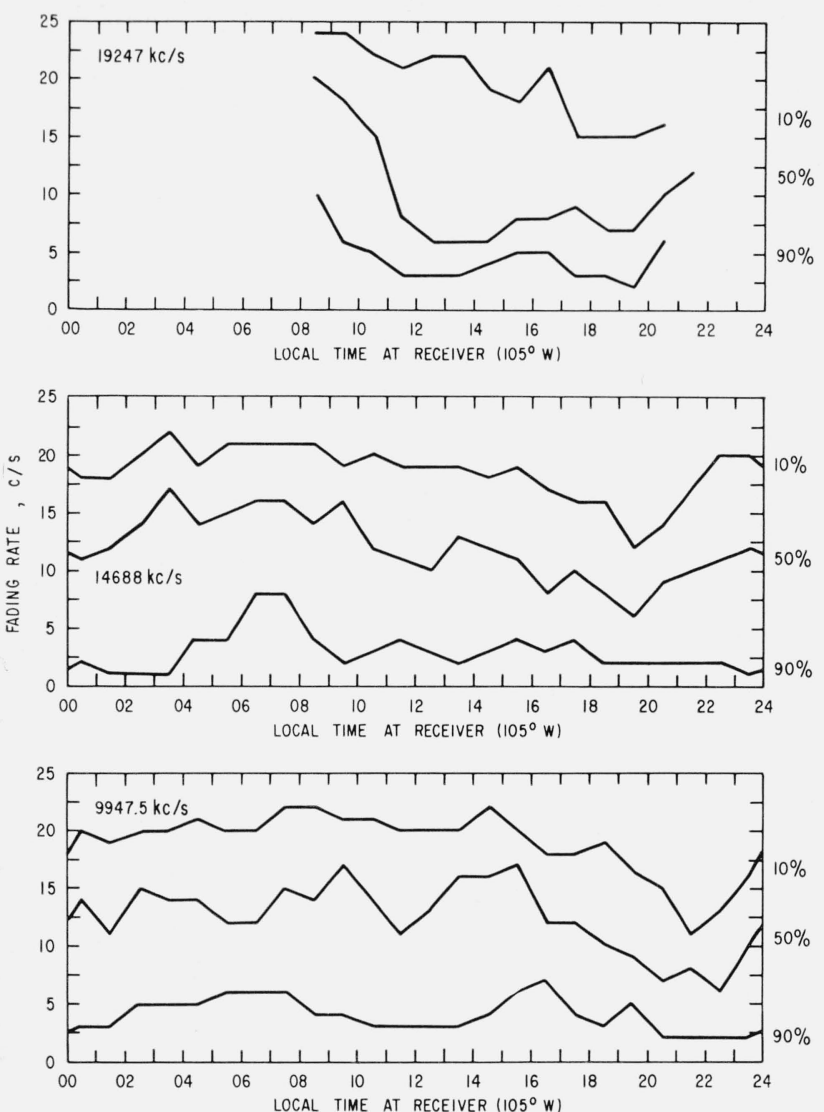

Figure 6. Diurnal variations of hourly maximum fading rates, January 1960.

Hourly maximum fading rates are exceeded for percentage of time indicated by curve parameters.

January 1960 , and show the 10,50 , and 90 percentile values of hourly maximum fading rates. It appears that there is a tendency for the higher fading rates to occur during the early morning hours. Figures 7 and 8 are distributions of hourly maximum fading rates for the months of October 1959 and January 1960. Distributions of 10 -min median fading rates for the same months are shown on figures 9 and 10 . From the data obtained, it was found that fading rates gradually increased from October to January, with the lowest fading rates being observed in October, and the highest fading rates being observed in January.

An attempt was made to determine if there were any characteristic changes in fading rates immediately preceding or following major magnetic fluctuations. The results of the analysis did not show any significant factor in this regard; however, fading rates were generally higher on disturbed days than on quiet days, as shown by comparing figures 11 and 12 .

The received median signal strengths are usually lowered in value by 10 to $20 \mathrm{db}$ when a period of fast fading occurs, although this is not always the case. Fading rates often change from 1 to $2 \mathrm{c} / \mathrm{s}$ to

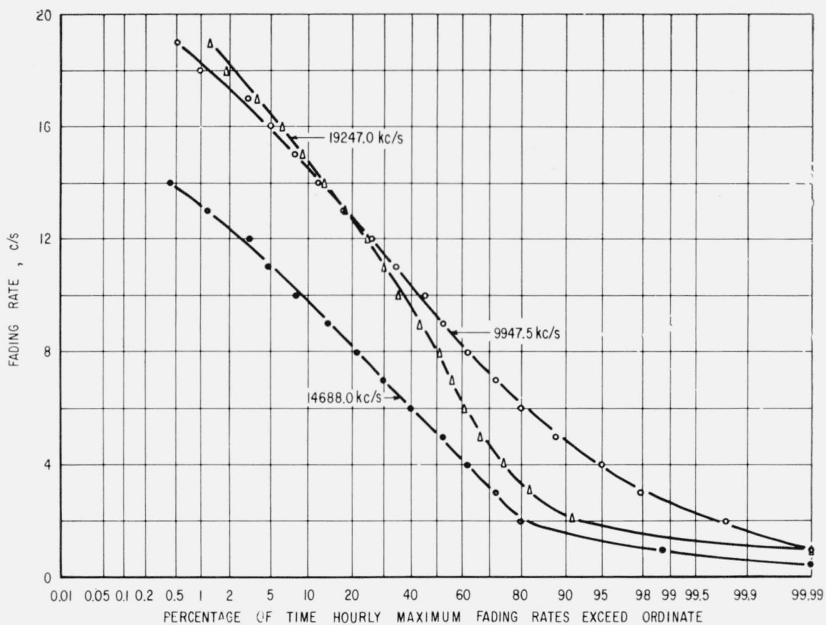

Figure 7. Distributions of hourly maximum fading rates, October 1959.

$9.9475 \mathrm{Mc} / \mathrm{s}-420 \mathrm{hr}$ $14.688 \mathrm{Mc} / \mathrm{s}-497 \mathrm{hr}$
$19.247 \mathrm{Mc} / \mathrm{s}-318 \mathrm{hr}$

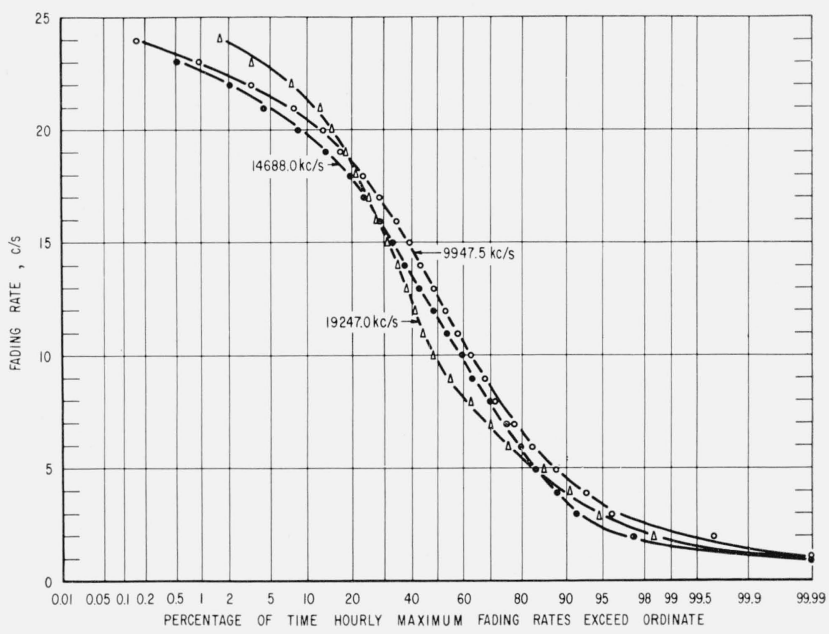

FIGURE 8. Distributions of hourly maximum fading rates, January 1960.

$9.9475 \mathrm{Mc} / \mathrm{s}-649 \mathrm{hr}$

$14.688 \mathrm{Mc} / \mathrm{s}-586 \mathrm{hr}$

$19.247 \mathrm{Mc} / \mathrm{s}-307 \mathrm{hr}$

values in the order of 6 to $15 \mathrm{c} / \mathrm{s}$ within a few minutes time. Change from the fast fading rates to slow fading rates occurs just as rapidly.

\subsection{Carrier Envelope Amplitude Distributions}

Typical amplitude distribution curves for the received carrier envelope voltages are plotted on figures 13 and 14 . It will be noted that several of the curves approach a Rayleigh distribution for the fading carrier envelope. When a Rayleigh distribution is obtained, the average fading rate is usually fairly low, although there are exceptions. During fast fading conditions, associated with auroral activity, the depth of fading is normally somewhat 


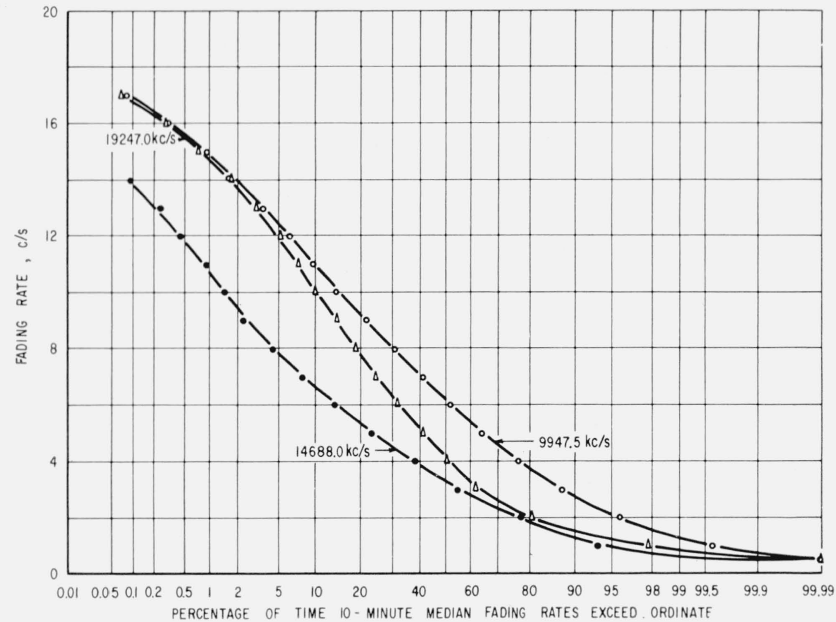

Figure 9. Distributions of 10-min median fading rates, October 1959.

$9.9475 \mathrm{Mc} / \mathrm{s}-253810$ - min samples

$14.688 \mathrm{Mc} / \mathrm{s}-220310-$ min samples

$19.247 \mathrm{Mc} / \mathrm{s}-15221 \mathrm{C}$ - min samples

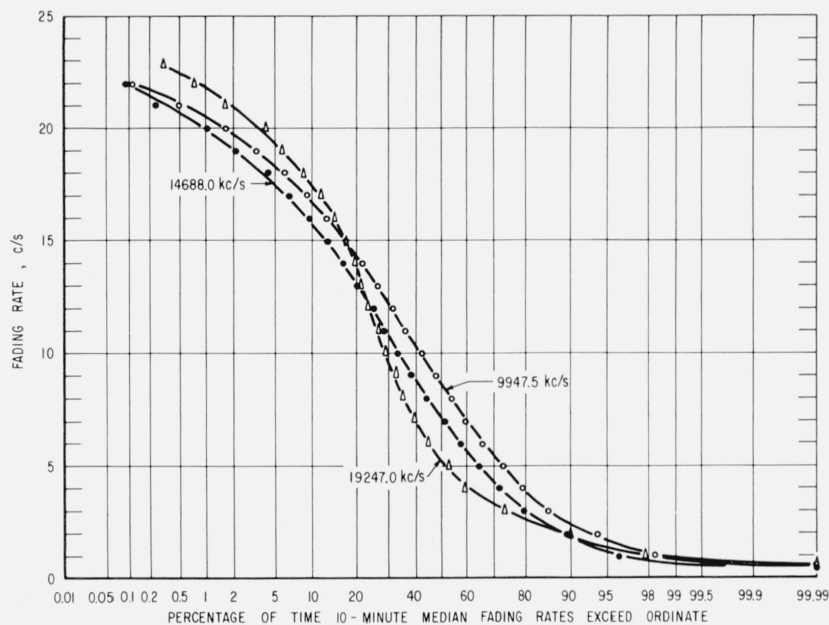

Figure 10. Distributions of 10-min median fading rates, January 1960

9.9475 Mc/s-3935 10-min samples

$14.688 \mathrm{Me} / \mathrm{s}-343510$ - min samples

19.247 Mc/s-1836 10 - min samples

reduced; this effect is indicated by the curvature at the lower level portions of some of the distribution curves. A statistical model of a constant vector plus a Rayleigh distributed vector as described by Norton, Vogler, Mansfield, and Short [1955], will produce shallow fading when the power in the constant vector is several times greater than the power in the Rayleigh distributed component.

\subsection{Distributions of Envelope Amplitudes for Various Minimum Durations of Fades}

The distributions of carrier envelope amplitudes for various minimum fade durations, figures 15 through 19, reflect the statistics of the depth of fading for certain minimum fade lengths. This type of informa-
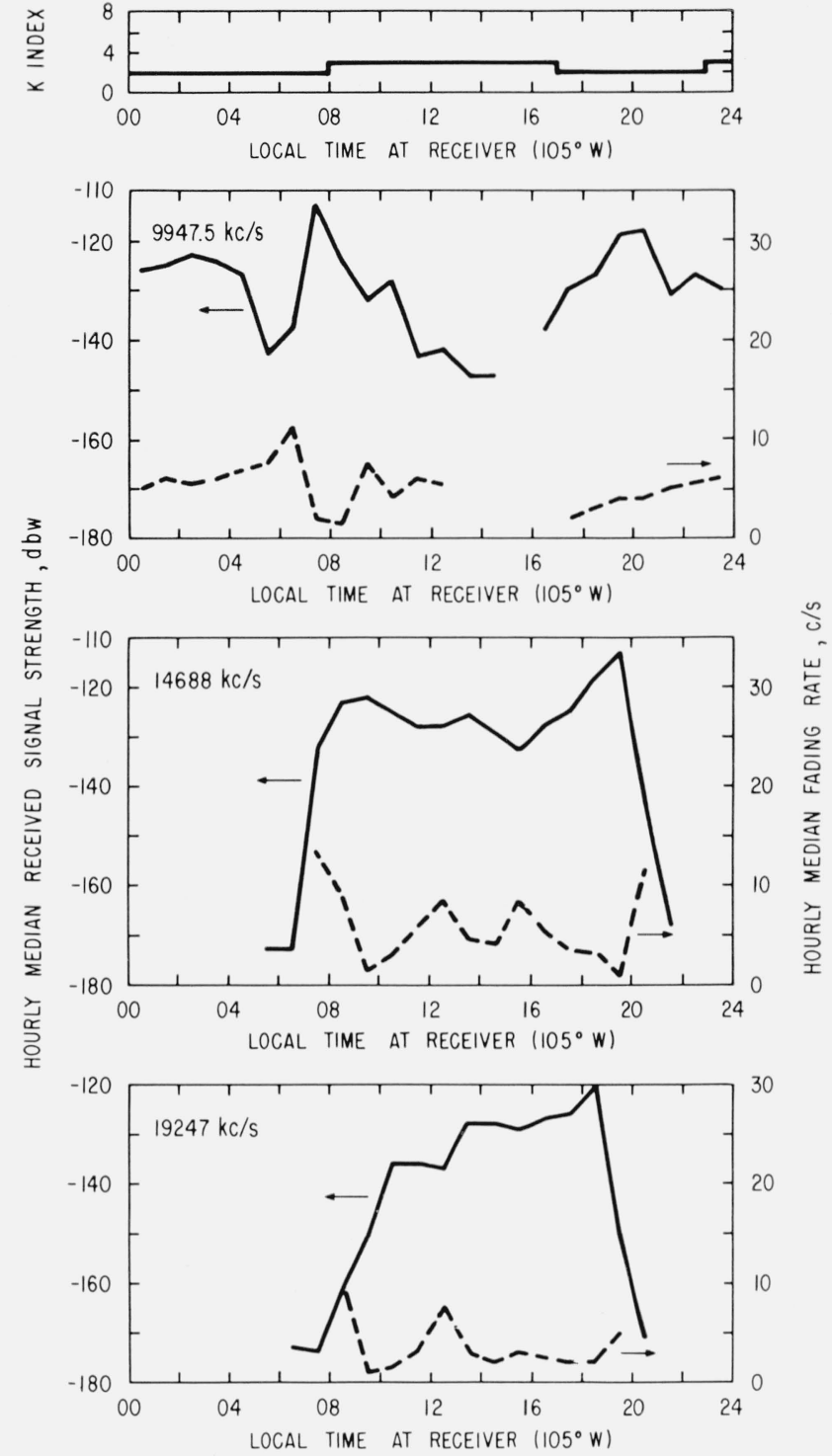

Figure 11. Diurnal variations of signal strength, fading rates. and Barrow, Alaska, magnetic activity index for quiet day, December 10, 1959

tion has been found to be quite useful as an aid in predicting performance of certain communication systems. As noted previously in connection with the amplitude distribution curves, when the characteristic auroral-type fast fading occurs, the fading depth is normally reduced, especially for the short fade durations, from that obtained with Rayleigh fading. However, one sample was obtained, figure 16 , which had the fairly fast fading rate of $6 \mathrm{c} / \mathrm{s}$ and maintained a nearly Rayleigh distribution for the very short minimum fade durations.

\subsection{Observed Fading Rates at Various Crossing Levels Versus Minimum Duration of Fades}

Some of the fade duration data obtained has been plotted so as to show the observed fading rates as a 

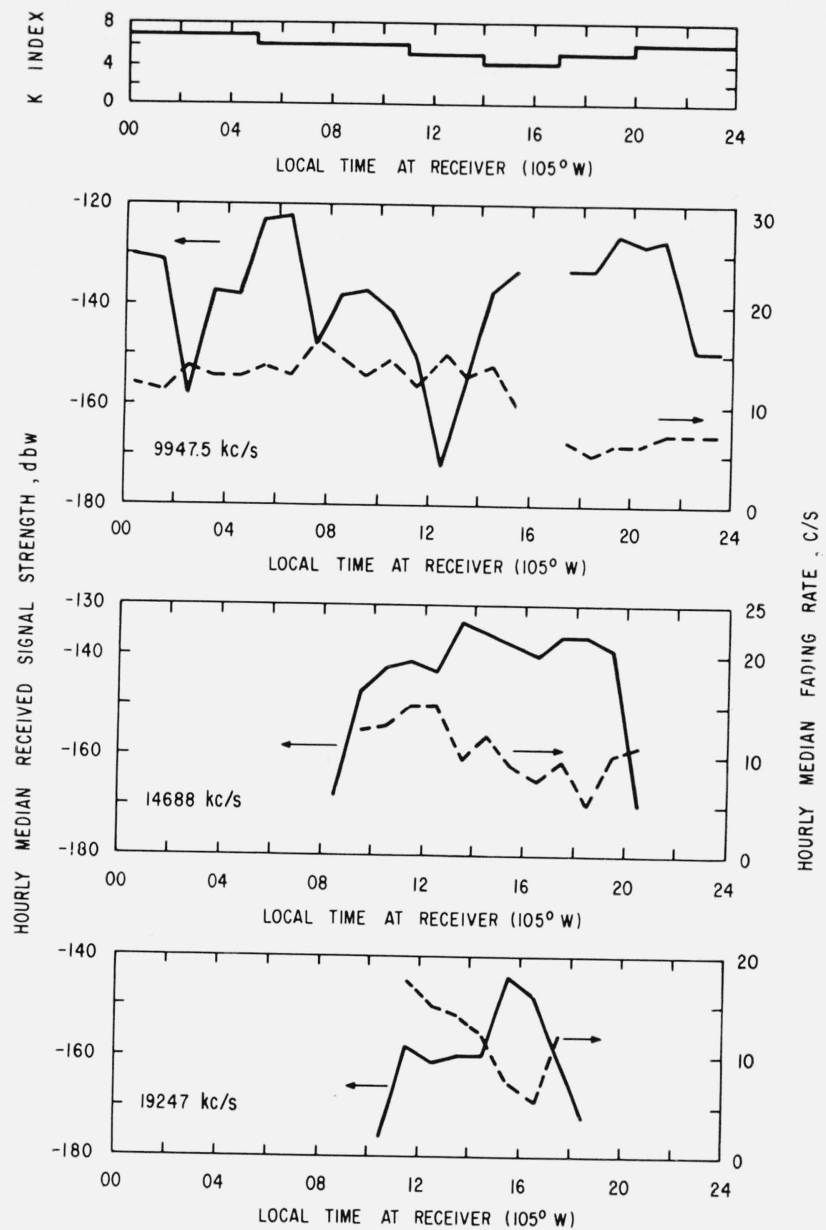

Figure 12. Diurnal variations of signal strength, fading rates, and Barrow, Alaska, magnetic activity index for disturbed day.

December 14, 1959

function of crossing levels and minimum duration of fades; figures 20 and 21 are examples of this information. It is interesting to note that the maximum crossing rate occurs near the median carrier level in all cases for short duration fades. At levels a few decibels above the median the crossing rate curves are fairly flat, indicating that only relatively long duration fades occur at these levels, while at the lower levels most of the fades are of short duration.

\section{Summary}

Statistical information has been obtained on certain experimentally observed fading characteristics of high-frequency continuous wave signals propagated over a long path through auroral regions. Fading rates in the order of $20 \mathrm{c} / \mathrm{s}$ have been observed for short periods at all of the observing frequencies. In most instances the received median carrier envelope level drops 10 to $20 \mathrm{db}$ when a period of fast fading sets in. Fading rates were generally higher on magnetically disturbed days than on quiet days. It was found for these observations that

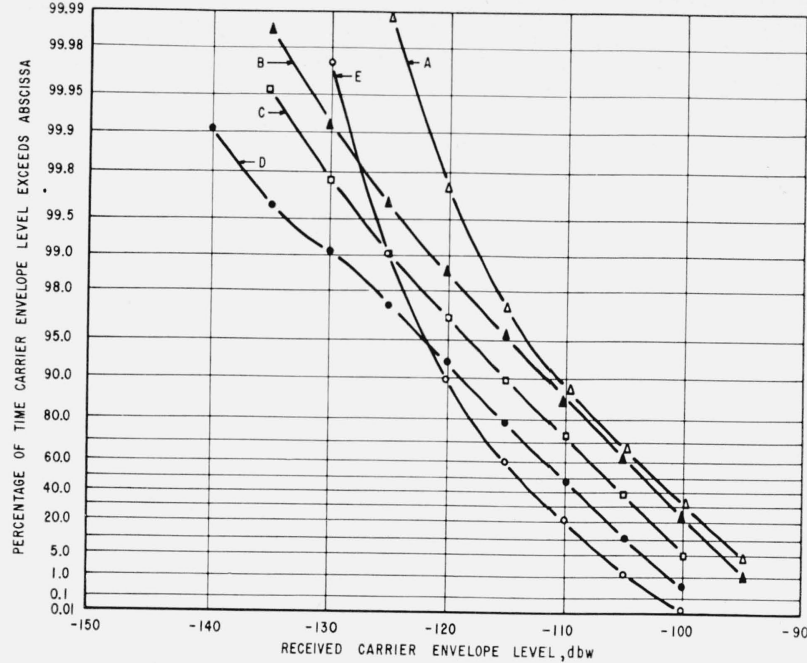

Figure 13. Amplitude distributions of carrier envelope$9.9475 \mathrm{Mc} / \mathrm{s}$.

Sampling period $200 \mathrm{sec}$

Low pass bandwidth of system $312 \mathrm{c} / \mathrm{s}(-6 \mathrm{db})$

Rayleigh distribution is straight line with slope of minus one.

A-Sept. 23,$1959 ; 0353 \mathrm{LTR}\left(105^{\circ} \mathrm{W}\right) 8 \mathrm{c} / \mathrm{s}$ average fading rate

B-Oct. 2,$1959 ; 2021 \overline{\mathrm{LTR}\left(105^{\circ} \mathrm{W}\right)} 1.5 \mathrm{c} / \mathrm{s}$ average fading rate

C-Oct. 2,$1959 ; 1933 \mathrm{LTR}\left(105^{\circ} \mathrm{W}\right) 1 \mathrm{c} / \mathrm{s}$ average fading rate

D-Oct. 2,$1959 ; 2217 \overline{\mathrm{LTR}}\left(105^{\circ} \mathrm{W}\right) 6 \mathrm{c} / \mathrm{s}$ average fading rate

E-Sept. 23, 1959; $0443 \mathrm{LTR}\left(105^{\circ} \mathrm{W}\right) 12 \mathrm{c} / \mathrm{s}$ average fading rate

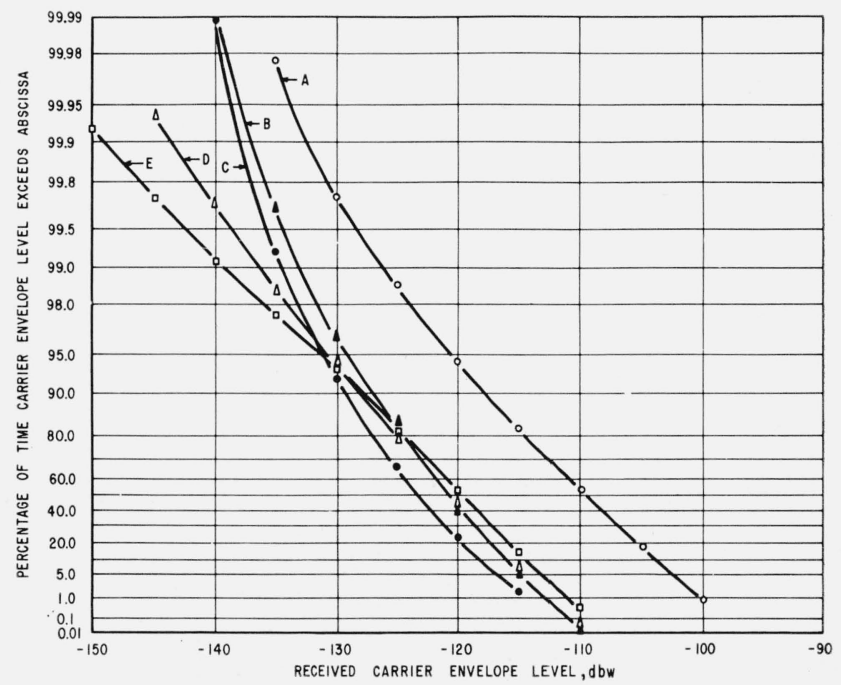

Figure 14. Amplitude distributions of carrier envelope19.247 Mc/s.

Sampling period $200 \mathrm{sec}$

Loss pass bandwidth of system $312 \mathrm{c} / \mathrm{s}(-6 \mathrm{db})$

Rayleigh distribution is straight line with slope of minus one

A-Sept. 15,$1959 ; 1337$ LTR $\left(105^{\circ} \mathrm{W}\right) 1 \mathrm{c} / \mathrm{s}$ average fading rate

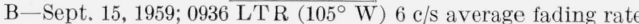

C-Sept. 15, 1959; $1142 \overline{\mathrm{LTR}\left(105^{\circ} \mathrm{W}\right)} 10 \mathrm{c} / \mathrm{s}$ average fading rate

D-Oct. 2, 1959; $1933 \overline{\mathrm{LTR}\left(105^{\circ} \mathrm{W}\right)} 1 \mathrm{c} / \mathrm{s}$ average fading rate

E-Nov. 20, 1959; $1544 \mathrm{LTR}\left(105^{\circ} \mathrm{W}\right) 2 \mathrm{c} / \mathrm{s}$ average fading rate

fading rates generally increased from October 1959 to January 1960. However, the autumnal equinoctial period in 1959 was unusually quiet from an auroraldisturbance standpoint and should not be considered typical. 


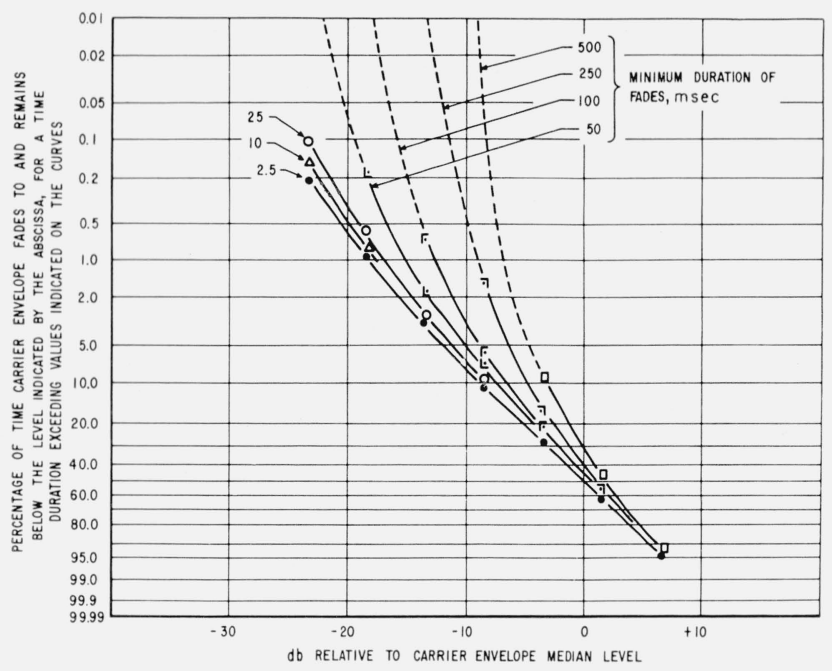

Figure 15. Distributions of carrier envelope amplitude for various minimum fade durations.

Sampling period $200 \mathrm{sec}$

Low pass bandwidth of system $312 \mathrm{c} / \mathrm{s}(-6 \mathrm{db})$

Median carrier to noise ratio $38.0 \mathrm{db}$

Average fading rate $1.5 \mathrm{c} / \mathrm{s}$

$9.9475 \mathrm{Mc} / \mathrm{s}$, October $2, j \mathrm{1959,} 1933 \mathrm{LTR}\left(105^{\circ} \mathrm{W}\right)$

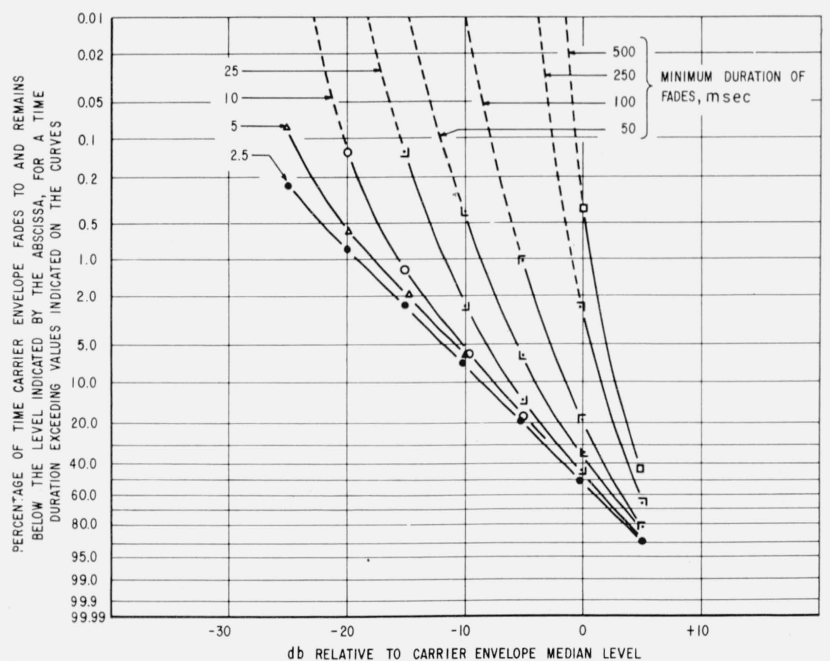

Figure 16. Distributions of carrier envelope amplitude for various minimum fade durations.

Sampling period $200 \mathrm{sec}$

Low pass bandwidth of system $312 \mathrm{c} / \mathrm{s}(-6 \mathrm{db})$

Median carrier-to-noise ratio $32 \mathrm{db}$

A verage fading rate $6 \mathrm{c} / \mathrm{s}$

$9.9475 \mathrm{Mc} / \mathrm{s}$, October 2,$1959 ; 2217 \mathrm{LTR}\left(105^{\circ} \mathrm{W}\right)$

Fading rates exceeded for small percentages of the time were highest at the higher of the three carrier frequencies observed; however, for fading rates exceeded for large percentages of the time, the lowest carrier frequency exhibited the highest fading rate.

The depth of carrier envelope fading, as deduced from the amplitude distribution measurements for all fades and for fades exceeding various minimum

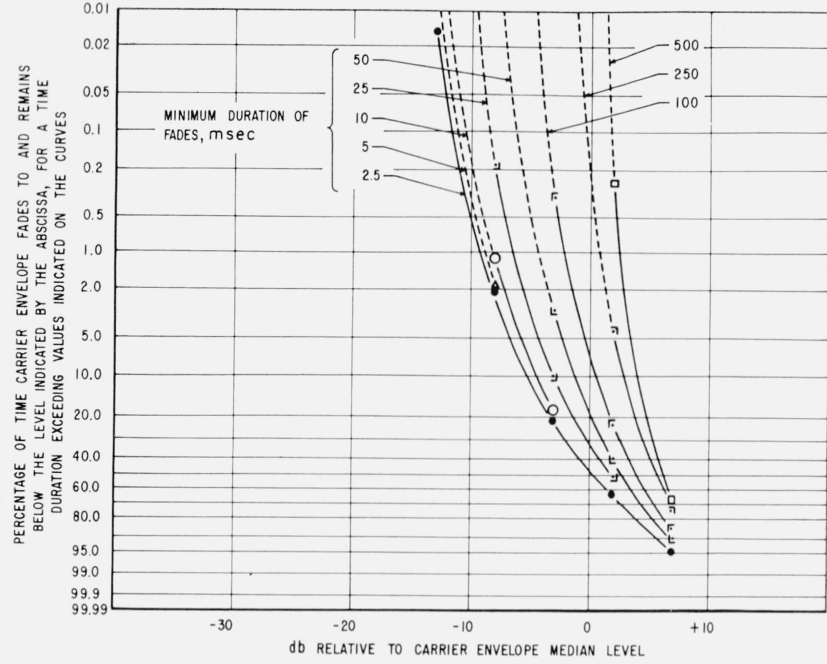

Figure 17. Distributions of carrier envelope amplitude for various minimum fade durations.

Sampling period $200 \mathrm{sec}$

Low pass bandwidth of system $312 \mathrm{c} / \mathrm{s}(-6 \mathrm{db})$

Median carrier-to-noise ratio $27.5 \mathrm{db}$

A verage fading rate $12 \mathrm{c} / \mathrm{s}$

$14.688 \mathrm{Mc} / \mathrm{s}$, December 23,$1959 ; 1435 \mathrm{LTR}\left(105^{\circ} \mathrm{W}\right)$

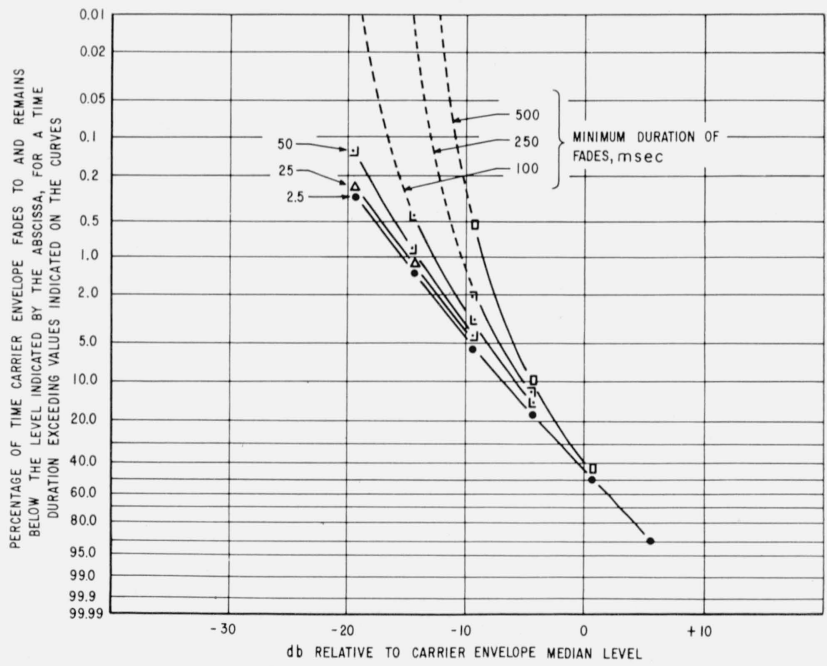

Figure 18. Distributions of carrier envelope amplitude for various minimum fade durations.

Sampling period $200 \mathrm{sec}$

Low pass bandwidth of system $312 \mathrm{c} / \mathrm{s}(-6 \mathrm{db})$

Median carrier-to-noise ratio $32.0 \mathrm{db}$

Average fading rate $1 \mathrm{c} / \mathrm{s}$

19.247 Mc/s, October 2, 1959; $1933 \mathrm{LTR}\left(105^{\circ} \mathrm{W}\right)$

time durations, is normally somewhat less for the auroral-type fast fading than for slow fading. This would seem to indicate the presence of a relatively steady component and a weaker fast-fluctuating component when fast fading conditions exist.

A Rayleigh distribution of carrier envelope amplitude was observed for a few of the periods, usually when the fading rates were fairly low. Most of the time, however, the carrier envelope amplitudes departed considerably from a Rayleigh distribution. 


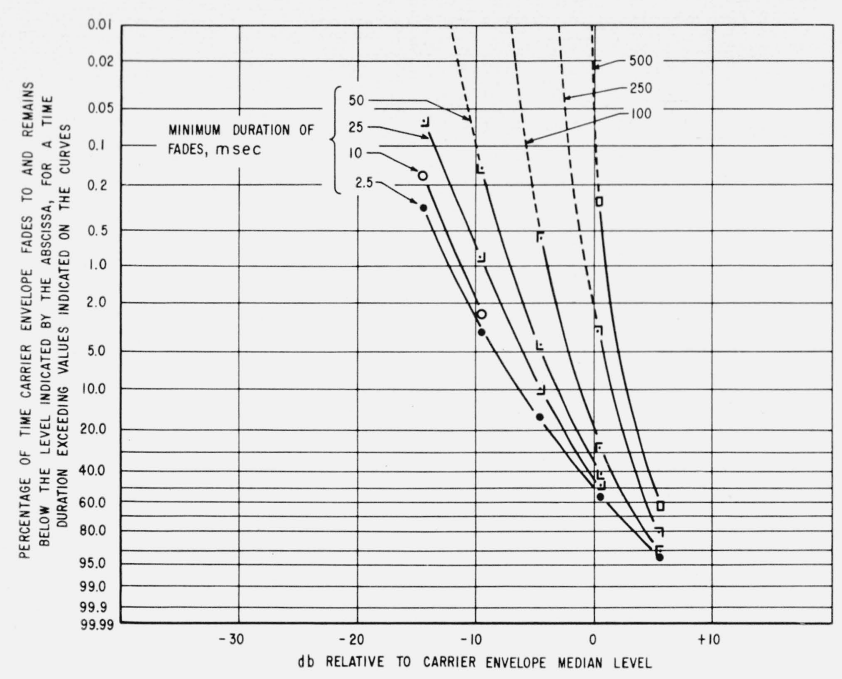

Figure 19. Distributions of carrier envelope amplitude for various minimum fade durations.

Sampling period 200 sec

Low pass bandwidth of system $312 \mathrm{c} / \mathrm{s}(-6 \mathrm{db})$

Median carrier-to-noise ratio $28.0 \mathrm{db}$

Average fading rate $7 \mathrm{c} / \mathrm{s}$

19.247 Mc/s September 15, 1959; 1936 LTR $\left(105^{\circ} \mathrm{W}\right)$

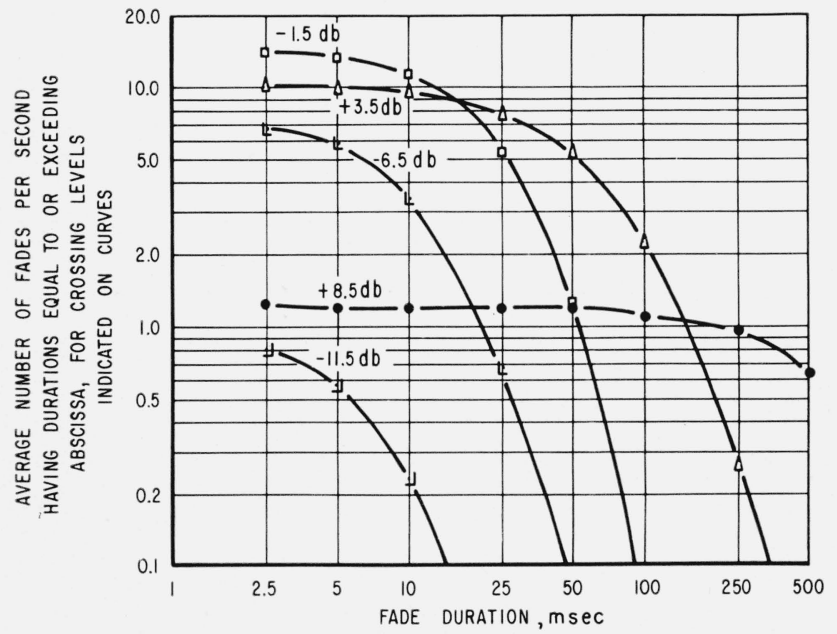

Figure 20. Fading rate versus minimum fade durations for various carrier levels relative to median carrier envelope level.

Sampling period $200 \mathrm{sec}$

Low pass bandwidth of system $312 \mathrm{c} / \mathrm{s}(-6 \mathrm{db})$

Median carrier-to-noise ratio $34 \mathrm{db}$

$9.9475 \mathrm{Mc} / \mathrm{s}$, September 23,$1959 ; 0443 \mathrm{LTR}\left(105^{\circ} \mathrm{W}\right)$

The experimental study reported herein was sponsored by the U.S. Air Force Wright Air Development Division, Wright-Patterson Air Force Base, Ohio. The assistance of the Arctic Research Laboratory, Office of Naval Research, Point Barrow, Alaska is gratefully acknowledged; Max Brewer, Director, and other personnel of that laboratory have provided logistics and housing for equipment installation and operation at Barrow. Other NBS personnel who have contributed substantially to the

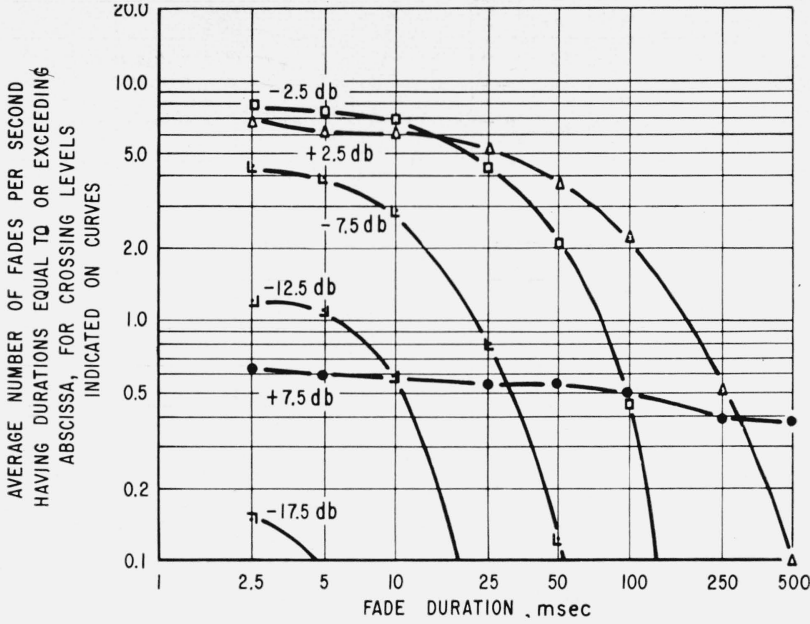

Figure 21. Fading rate versus minimum fade durations for various carrier levels relative to median carrier envelope level. Sampling period $200 \mathrm{sec}$

Low pass bandwidth of system $312 \mathrm{c} / \mathrm{s}(-6 \mathrm{db})$

Median carrier-to-noise ratio $40 \mathrm{db}$

$14.688 \mathrm{Mc} / \mathrm{s}$, September 15, 1959; $0910 \mathrm{LTR}\left(105^{\circ} \mathrm{W}\right)$

project include: W. B. Harding, C. H. Johnson, G. E. Wasson, and J. L. Workman (Barrow, Alaska). The authors also thank Miss Freda L'Manian for her assistance in preparing the manuscript.

\section{References}

Aggarwal, K. K., Statistical analysis of fading on short-wave transmissions, J. Inst. Tel. Engrs. (New Delhi) 5, No. 4, 230-237 (Sept. 1959).

Grisdale, G. L., J. G. Morris, and D. S. Palmer, Fading of long-distance radio signals and a comparison of space and polorization-diversity reception in the $6-18 \mathrm{Mc} / \mathrm{s}$ range, Proc. Inst. Elec. Engrs. 104B, No. 13, 39-51 (Jan. 1957).

Koch, J. W., W. B. Harding, and R. J. Jansen, Fading rate recorder for propagation research, Electronics 32, No. 51, 78-80 (Dec. 18, 1960).

McNicol, R. W. E., The fading of radio waves of medium and high frequencies, Proc. Inst. Elec. Engrs. pt. III 96, No. 44, 517-524 (Nov. 1949).

Norton, K. A., P. L. Rice, H. B. Janes, and A. P. Barsis, The rate of fading in propagation through a turbulent atmosphere, Proc. I.R.E. 43, No. 10, 1341-1353 (Oct. 1955).

Norton, K. A., L. E. Vogler, W. V. Mansfield, and P. J. Short, The probability distribution of the amplitude of a constant vector plus a Rayleigh-distributed vector, Proc. I.R.E. 43, No. 10, 1354-1361 (Oct. 1955).

Rice, S. O., Mathematical analysis of random noise, pts. I \& II, Bell System Tech. J. 23, No. 3, 282-332 (July 1944).

Rice, S. O., Mathematical analysis of random noise, pts. III \& IV, Bell System Tech. J. 24, No. 1, 46-156 (Jan. 1945).

Rice, S. O., Statistical properties of a sine wave plus random noise, Bell System Tech. J. 27, No. 1, 109-157 (Jan. 1948).

Rice, S. O., Distribution of the duration of fades in radio transmission: Gaussian noise model, Bell System Tech. J. 37, No. 3, 581-635 (May 1958).

Yeh, K. C., and O. G. Villard, Jr., Fading and attenuation of high-frequency radio waves propagated over long paths crossing the auroral, temperate, and equatorial zones, J. Atmospheric and Terrest. Phys. 17, 255-270 (1960).

(Paper 66D2-183) 